\title{
Identifying the Current Trend of Sustainable Development of Asia
}

\author{
H. M. T. R. Herath ${ }^{1}$, A. C. Udage $^{2}$ and R. M. P. S. Rathnayaka ${ }^{3}$ \\ ${ }^{1}$ Department of Agricultural Economics and Business Management, University of Peradeniya, Sri Lanka \\ ${ }^{2 \& 3}$ Department of Export Agriculture, Uva Wellassa University, Sri Lanka \\ E-mail: ruviniherath92@gmail.com, ashanranga@gmail.com, prabodha.rathnayaka965@gmail.com
}

\begin{abstract}
By the end of the last millennium, "sustainable development" was the most widely discussed topic among scholars, policy makers and diplomats. Meanwhile, over the past decades, many Asian economies have achieved striking levels of economic growth for the betterment of the human life. However, it has also been accompanied by substantial environmental degradation. The purpose of this paper is to provide a brief overview of the current trends in sustainable development in Asia through indicating the current position of 44 Asian countries with respect to each sustainable dimension, by mapping the countries in order to show spatially where they stand in sustainable development and by statistically finding the existence of an association in each sustainability criterion. For this study secondary data were utilized and those were extracted from Sustainability Society Index (SSI). The sixth edition, SSI-2016 was used on this behalf. Data were descriptively analyzed using Minitab 17 and Excel while the required maps were generated using Arc Map 10.1 Geographic Information System (GIS) by ESRI. The association among the three dimensions, Human, Environmental and Economic wellbeing, was found out using Pearson Correlation. From the analysis we could find that there is no association between environmental well-being and human well-being Nevertheless, there is an association between the economic well-being and the human well-being and the same was resulted for the economic and environmental well-being.

Keywords: Asia, Current Trend, GIS, Ranking, Sustainable Development
\end{abstract}

\section{INTRODUCTION}

Sustainable development is a phrase which has many definitions. It has been a concept that had a major focus in recent years. According to United Nations sustainable development is defined as "development that meets the needs of the present without compromising the ability of future generations to meet their own needs" (UN, 2010). Sustainability has become a major necessity for the wellbeing of the earth as its natural resources are depleting fast. Sustainable development has agendas in many levels such as world level, continent level, country level and etc. Addressing sustainable development considering one aspect/element is not a successful approach because sustainable development has three major elements; Environment, Society, Economy, also known as three Ps; Planet, People and Profit (Dutton, 2017). Achievement of sustainability in these three elements is a must to accomplish successful sustainable development. To assess the sustainability with comprehension, indices should be used. These indices must come under the three elements and the indices used should be quantifiable as qualitative indices only give vague outcome from the results. Without a framework to define and guide the measurements of sustainable societies, policy management will resort to assessments that are less transparent, more subjective and that lack standardization across locations and through time (Saisana \& Philippas, 2012).

Sustainable Society Foundation has started developing quantifiable indices to measure sustainability since 2006. These measures are known as Sustainable Society Index (SSI) that aims to be a comprehensive and quantitative method to measure and monitor the health of coupled human-environmental systems (Saisana \& Philippas, 2012). Sustainable Society Index integrates the above discussed elements to give a clear idea of a country's state of sustainable development. SSI integrates measurable indicators which provide a compass to sustainability in a country. Studies on sustainability have been done in abundance over last few decades. These studies clearly show that there is large number of indices which attempts to assess the sustainability of a nation.

Even though studies have been done to identify the interrelationship of the three elements of sustainable development, the influence of economic development on human and environmental wellbeing have not been studied sufficiently in the recent years. Most of the countries with better economies have failed to sustain environmental wellbeing. As a result, human wellbeing has also taken a turn for the worse in recent years. Results of World Economic and Social Survey (2013) reveals that more than one billion people are still living in extreme poverty, and income inequality within and among many countries has been rising; at the same time, unsustainable consumption and production patterns have resulted in huge economic and social costs and may endanger life on the planet (United Nations, 2013).

Human and Environmental Wellbeing are the major goals in sustainable development. Human Wellbeing without Environmental Wellbeing is a dead end; Environmental Wellbeing without Human Wellbeing makes no sense, at least not for human beings. Economic Wellbeing is not a goal in itself. It is integrated as a condition to achieve Human and Environmental Wellbeing. It can be considered as a safeguard to wellbeing (Sustainable Society Foundation, 2017). 
As most of the countries have been concentrating only on economic development, neglecting the sole purpose of it; human and environmental wellbeing, damage to the global environment has been reaching critical levels and threatens to lead to irreversible changes in global ecosystems. Most visibly in climate change, critical thresholds have already been exceeded thus, endangering the environmental wellbeing as well as the human wellbeing.

Current report will assess the data of 21 quantifiable indices in seven categories. These seven categories are grouped under three elements; Human wellbeing, Environmental wellbeing and Economic wellbeing. The research is preceded by making use of these three elements.

This study aims to identify the current trend of Asian world towards sustainable development and how elements of sustainable development influenced on each other. In addition to that, the study is aiming to assess whether human and environmental wellbeing is a possibility while maintaining an ideal economic growth and how economically sound countries have performed in human wellbeing and environmental wellbeing and vice versa.

There are similar researches carried out regarding sustainability, but they were conducted in late 90's and early years of the $2^{\text {nd }}$ millenium and they used the sustainability indices as the criteria.

Therefore, we found that it is necessary to conduct such a study based on recent data which would describe the current pathway of sustainability. Moreover, to be precise we used the three pillars of sustainability as our criteria. There are few researches carried out combining Asia and sustainability. So, through this research we intend to fill this research gap by explaining how the urbanization and rapid industrialization in Asia has gone hand in hand with sustainability.

\section{A. Objectives of the Study}

\section{General Objective}

To identify the current trend of sustainable development in Asia.

\section{Specific Objectives}

1. To rank the countries in Asia according to the scores in the three sustainability criteria.

2. To map the countries in Asia according to each dimension.

3. To statistically find the existence of an association in each sustainability criterion.

4. To find the progress of Sri Lanka in sustainability.

\section{LITERATURE REVIEW}

\section{A. Three Pillars of Sustainability}

Sustainable development is a contested concept, with theories shaped by people's and organizations' different perspectives, which in turn influence how issues are formulated and actions proposed. It is embraced by big business, governments, social reformers and environmental activists, all of which put their own interpretation on what sustainable development means. (Giddings, 2002) It can be deciphered as an integrative concept which considers environmental, social, and economic aspects as three fundamental dimensions. These three dimensions have been denoted as pillars of sustainability, which reflect that responsible development requires consideration of natural, human, and economic capital or simply, the planet, people, and profits (Schoolman et al., 2012).

\section{B. Economic Sustainability}

The economists focus on various kinds of “capital” (manmade, natural, human, and social) that should be sustained (World Bank, 2006). According to Markandya and Pearce (1988), sustainability might be redefined so that the use of resources today should not reduce real incomes in the future because sustainability requires that the conditions necessary for equal access to the resource base be met for each subsequent generation. From this, it follows that future economic progress will be increasingly dependent on the sustained integrity of the resource and environmental base (Hamrin, 1983).

Given the current financial and economic crisis, the economic aspects of development are under close scrutiny. The economic sustainability shows that maintaining economic growth is an essential and universally accepted objective for the broad public.

It should be noted that economic growth has been the most important policy goal across the world for the last five decades. It is the reason why it has been difficult to find a balance between sustainability and the economic growth of countries. As suggested by Moldan et al., (2012), the economic sustainability could be an example of how to change the approach to economic growth and how to conceive of a new economy in terms of sustainable development.

The current global economic crisis thus brought into focus the economic pillar and questioned the sustainability of development based on economic progress. This means fully addressing the economic issues on their own merits and in no apparent connection with the environmental aspects.

\section{Environmental Sustainability}

The term, “environmental sustainability” itself was probably first coined by scientists at the World Bank. Originally, the 
term "environmentally responsible development" was used (World Bank, 1992) and with the passage of time as identified by Serageldin and Streeter (1993), "environmentally sustainable development” was employed. Finally, the concept of environmental sustainability was developed (Goodland, 1995).

Goodland (1995) declares that the environmental sustainability "seeks to improve human welfare by protecting the sources of raw materials used for human needs and ensuring that the sinks for human wastes are not exceeded, in order to prevent harm to humans”. Goodland's conceptualization of environmental sustainability fits into the resource-limited ecological economic framework of "limits to growth".

Current Opinion in Environmental Sustainability is the first scholarly journal reviewing and synthesizing research on sustainability and environmental change. It provides its audience with a new vehicle to provide timely updates on science and the research programs. It focuses on six areas: Climate systems, Human settlements and habitats, Energy systems, Terrestrial systems, Carbon and nitrogen cycles, Aquatic systems(Moldan et al., 2012).

\section{Social Sustainability}

The social dimension has commonly been recognized as the weakest 'pillar' of sustainable development, notably when it comes to its analytical and theoretical underpinnings. (Hansmann et al., 2012). When it comes to the definition, Black defined social sustainability as "the extent to which social values, social identities, social relationships and social institutions can continue into the future" (Black, 2004). Gilbert et al. (1995) perceive the social pillar of sustainable development as follows: "Social sustainability requires that the cohesion of society and its ability to work towards common goals be maintained. Individual needs, such as those of health and well-being, nutrition, shelter, education and cultural expression should be met”.

However, these and other definitions are more or less statements of the general goals of social policy rather than serious attempts to define the social dimension of sustainable development, as noted by Colantonio (2007). And yet, it is precisely the social "pillar" of sustainable development that is probably the most important and critical for the long-term survival of human civilizations as shown in Jared Diamond's insightful study of past (and contemporary) societies (Diamond, 2005).

As per the point of view of Woolcock (2001) in the past decade, there has been a resurgence of interest towards the social dimensions of development, which can be attributed to the fall of communism, the ostensible difficulties of creating market institutions in transitional economies, the financial crises in Latin America, East Asia, and Russia, and the persistent problems of unemployment and social marginalization in even the most prosperous economies.
Even less attention has so far been paid to the linkages between the social and the environmental dimensions. Nevertheless, it can be argued that the essence of sustainable development lies precisely at the interfaces and trade-offs between the often conflicting objectives of economic and social development, and environmental protection. (Hansmann et al., 2012)

The social dimension is clearly different from the environmental one, since it is bipolar-it refers both to individual and collective levels; it is reflexive-our perceptions and interpretations of the objective social conditions change the behaviour of individuals and social collectives, hence influencing the objective conditions themselves; and it is immaterial-while concrete material circumstances lie at the basis of the 'social', the social phenomena themselves are essentially immaterial and therefore difficult to grasp and analyze, in particular quantitatively (Empacher, 2002).

\section{E. Sustainable Development in Asia}

Asia is the largest continent of the world consisting of 48 countries (according to United Nations). Countries in Asia have extremely diverse climatic conditions. Asia has some of the wealthiest countries as well as some of the poorest countries in the world. In recent years Asian countries have experienced fastest economic growth in history.

However, this economic growth is not reflected well in the sustainable development of the continent as environmental degradation, economic uncertainty, and widening of gaps between rich and poor has increased immensely (United Nations ESCAP, 2018). As United Nations Economic and Social Commission for Asia and the Pacific (UNESCAP) states, people and planet must be at the center of the efforts to build an inclusive, sustainable, and resilient future. Economic growth of the continent should be aligned with sustainable development objectives, moving away from conventional development paradigms based on trade-offs between the three pillars of sustainable development.

Brandon and Ramankutty (1993) have described the state of the environment in Asia in the following terms: Economic and population growth has led to severe negative impacts on the Asian environment. Pressure on the region's resources is intense and growing. There are serious problems in the areas of urban environmental degradation, industrial pollution, atmospheric emissions, soil erosion and land degradation, degradation of water resources, deforestation, and loss of natural habitat. Questions about the sustainability of current economic growth are more than an abstraction concerning limits to growth. The real costs of environmental degradation are mounting, taking the forms of increasing health costs and mortality, reduced output in resource based sectors, and irreversible loss of bio-diversity and overall environmental quality. 
Over the past four decades, the Asian economies' have experienced a wide range of economic growth rates ranging from $8.7 \%$ per annum in Taiwan, 8.0 in South Korea, and $7.0 \%$ in Thailand to $4.2 \%$ in India, $3.9 \%$ in Sri Lanka, and 3.0 in Bangladesh (Islamand Jolley,1996.).

In 2015 United Nations started a program called 'The 2030 Agenda for Sustainable Development' with the Sustainable Development Goals (SDGs). 17 Sustainable Development Goals (SDGs) represent a universal call to end poverty, protect the planet, and ensure peace and prosperity for all. They form part of the 2030 Agenda for Sustainable Development adopted by 191-member states of the United Nations in September 2015 (Asian Development Bank (ADB), 2019).

After three years of commencement of 2030 agenda, according to a UN progress report, the Asia Pacific region is failing to meet targets for almost two-thirds of the United Nations Sustainable Development Goals (SDGs) (Daniel, 2018). The inequality between the rich and poor has increased in the recent years. In addition to that, environmental degradation of Asia has increased exposing the poor and disadvantaged to many health issues putting their life at risk (Zahedi, 2018).

Apart from that, the actions taken to protect, restore and promote terrestrial ecosystems have not been sufficient at all. Forests of the Asian region have degraded increasingly. As a whole biodiversity of the region is on the regress. Climatic changes in the world have also impacted the Asian countries more.

Among all the concerns of sustainable development in Asian countries most pressing concern has been the failure to reduce the inequalities. In fact, the inequalities among people have increased. Compared to the reports of year 2000, after 17 years, some countries have enjoyed much stronger growth than others but, not always been successful in sharing its proceeds equitably.

For Southeast Asia, not only has the sub region not succeeded in reduced inequalities but it is the only sub region with "widening inequalities (Daniel, 2018). UNESCAP report further states that Asian continent risk further to continue the inequality, notable in gender equality, income disparity and access to resources. This, in future will increase the climatic and economic migrants in the region as well.

As sustainable development focuses on three pillars; Environment, Society, Economy and Asian continent already falling behind to achieve and sustain the well-being of Environmental, Social and Economic wellbeing, the continent will have to take greater stride towards sustainable development sooner rather than later.

\section{METHODOLOGY}

\section{A. Data}

Secondary data collected from Sustainability Society Index (SSI) were used for the research study. The sixth edition, SSI-2016 was used on this behalf. Data set can be accessed by the following link: http://www.ssfindex.com/data-allcountries/.Although there are 48 countries in Asian continent the data were available regarding 44 countries only. Therefore, in our research we have considered only 44 countries.

\section{B. Calculation Methodology}

For lack of a scientific basis for the attribution of different weights to the indicators, every indicator has received the same weight for the aggregation into dimensions.

All totals, be it for the world as a whole, per income class or per region, are weighted for population size. This means that an inhabitant of Uzbekistan has the same weight as an inhabitant of China.

\section{Calculation Formulae}

Calculation formulas can be found in the following links http://www.ssfindex.com/ssi2016/wp content/uploads/pdf/calculation-formulas-2016.pdf

\section{Data Analysis}

\section{Descriptive Analysis}

The data extracted from the SSI database were first input into tabular format using Excel and then were analyzed using Minitab 17 and Excel while generating required maps using ArcMap 10.1 Geographic Information System (GIS) by ESRI. Descriptive analysis was supported using histograms, and maps generated via GIS.

\section{a. Ranking}

First the countries were ranked using Excel, separately, according to the Human, Environmental and Economic well-being of each country. In each dimension, separate colors were assigned to a group of countries based on their sustainability ranking. The top $20 \%$ in terms of sustainability according to each metric were coloured in dark green. The next 20\% were colored light green, the following $20 \%$ yellow, the following $20 \%$ orange, and the bottom $20 \%$ red. This visualization was deliberately chosen to provide the reader with a holistic view of the discrepancies across different nations in Asia, which is otherwise difficult to grasp from the raw numbers. Then giving special attention to Sri Lanka, the progress of sustainable development of Sri Lanka was depicted graphically by making use of Excel. 


\section{b. Map Generation}

Results are also conveyed by mapping countries according to ranking for each dimension. The intent is to provide a spatial distribution of the results using ArcMap to better capture a holistic assessment of sustainability in whole Asia. As in the Excel table, countries are colour-coded for each dimension based on their ranking. (Top 20\% dark green, next $20 \%$ light green, middle $20 \%$ yellow, next $20 \%$ orange and bottom 20\% red) Map of the world (Shapefile) was downloaded from the http://thematicmapping.org/ downloads/world_borders.php ArcMap 10.1 was used to isolate the Asian continent from the rest of the world.

\section{E. Statistical Analysis}

The association among the three dimensions, Human, Environmental and Economic well-being, was found out using Pearson Correlation which measures the degree to which a linear predictive relationship exists between two variables.

If both variables increase together across countries, a positive correlation results in a value from0 to +1.0 . Conversely, an inverse relationship between the metrics would yield a negative correlation coefficient, between 0 and -1.0

\section{RESULTS AND DISCUSSION}

\section{A. Descriptive Analysis}

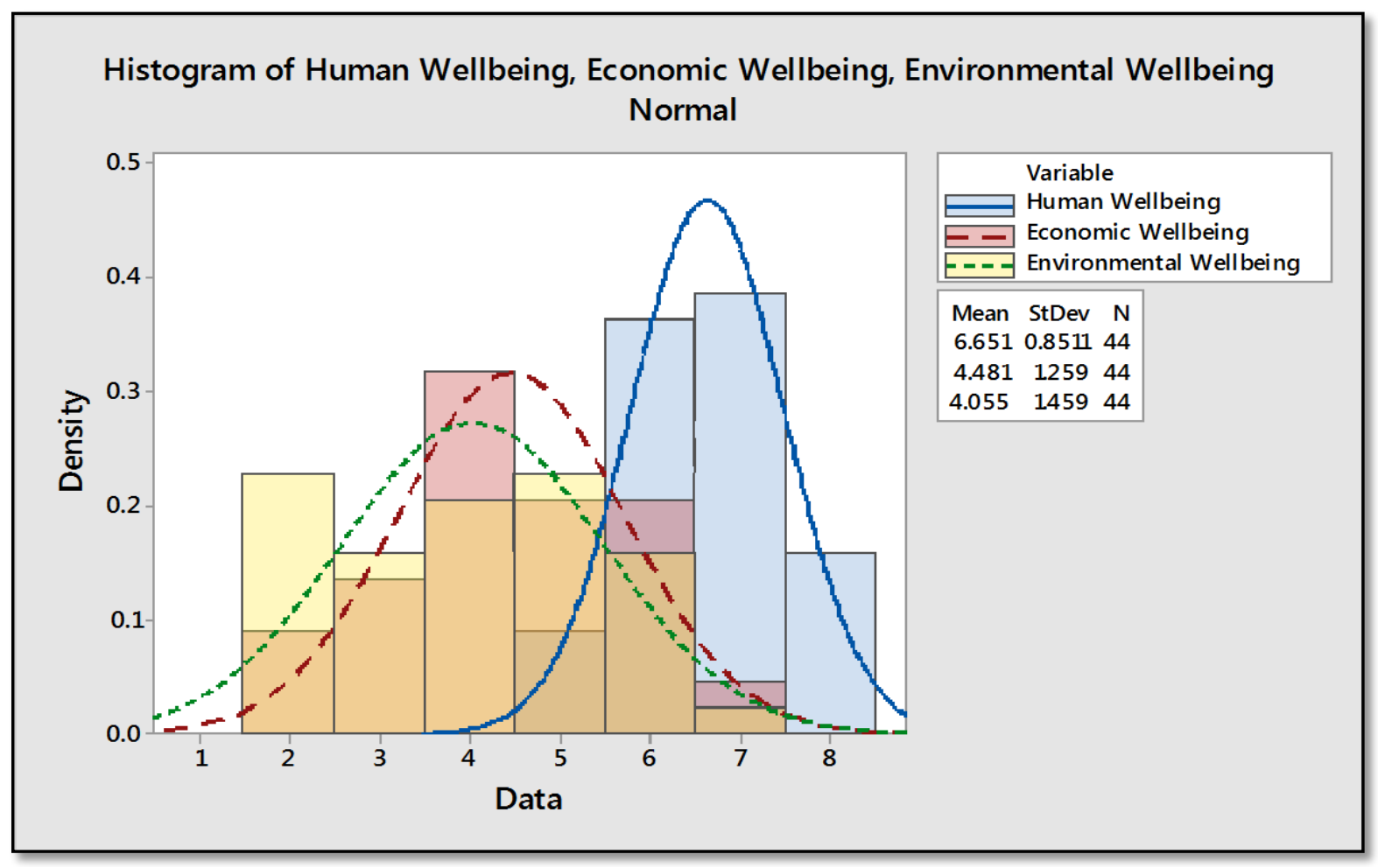

Fig. 1 Histogram of Human Well-being, Economic Well-being and Environmental Well-being

According to the histogram it is obvious that economic well-being of the considered region is symmetrically distributed taking a mean value of 4.5. At a glance we can observe that human well-being of the region is highly skewed to the left side indicating that most of the countries in the region experience higher standards of living.

The corresponding mean value for this component is 6.7. On the other hand, the environmental well-being of the Asian countries seems to be slightly right skewed indicating that in most of the considered countries the well-being of the environment is slightly lesser than the average. It takes a low mean value as 4.0 .
Table I shows the ranking of the countries (alphabetical order) in each different dimension. No row appeared as one solid color indicating that no country ranked in the same level for all 3 dimensions. In fact, the majority of rows had several colors suggesting a lack of consistency among the dimensions. The highest ranks in human well-being, environmental well-being and economic well-being are possessed by Japan, Nepal and UAE respectively whereas the lowest in all dimensions are experienced by Yemen, Qatar and again Yemen respectively.

Both Lebanon and Iraq as countries take a very low rank in both human and economic well-being. In contrast, South Korea is placed at the second rank in both above mentioned dimensions. 
TABLE I RANKING OF COUNTRIES

\begin{tabular}{|c|c|c|c|c|c|c|}
\hline Country & $\begin{array}{c}\text { Human } \\
\text { Well-being }\end{array}$ & Rank & $\begin{array}{c}\text { Environmental } \\
\text { Well-being }\end{array}$ & Rank & $\begin{array}{c}\text { Economic } \\
\text { Well-being }\end{array}$ & Rank \\
\hline Armenia & 7.610986 & 5 & 4.044320 & 21 & 3.194760 & \\
\hline Azerbaijan & 7.288231 & 11 & 3.936858 & 23 & 5.737162 & 7 \\
\hline Bangladesh & 6.453437 & 25 & 5.362143 & 9 & 4.272941 & 25 \\
\hline Bhutan & 6.578692 & 23 & 4.232206 & 20 & 4.043458 & 27 \\
\hline Cambodia & 5.965142 & & 6.351557 & 3 & 4.463252 & 21 \\
\hline China & 6.404098 & 29 & 3.823469 & 26 & 5.482337 & 12 \\
\hline Cyprus & 7.996489 & 4 & 4.508076 & 18 & 3.496650 & 35 \\
\hline Georgia & 7.515914 & 7 & 4.908345 & 15 & 3.962181 & 29 \\
\hline India & 6.308954 & 30 & 5.135651 & 12 & 4.255323 & 26 \\
\hline Indonesia & 6.794939 & 19 & 5.988954 & 5 & 5.148779 & 15 \\
\hline Iran & 6.826982 & 18 & 3.118320 & 32 & 4.413059 & 22 \\
\hline Iraq & 5.150639 & & 3.203492 & 31 & 2.138450 & \\
\hline Israel & 6.958701 & 15 & 3.396134 & 29 & 5.519155 & 10 \\
\hline Japan & 8.454430 & 1 & 3.624813 & 27 & 3.694159 & 32 \\
\hline Jordan & 6.405990 & 28 & 3.354571 & 30 & 3.020922 & \\
\hline Kazakhstan & 7.608669 & 6 & 2.677291 & 34 & 5.346017 & 14 \\
\hline Korea, North & 6.241932 & 32 & 5.555662 & 7 & 3.875442 & 30 \\
\hline Korea, South & 8.342930 & 2 & 2.496521 & 35 & 6.835697 & 2 \\
\hline Kuwait & 6.257804 & 31 & 2.341808 & 39 & 6.301642 & 5 \\
\hline Kyrgyz Republic & 6.979474 & 13 & 4.945938 & 14 & 2.245563 & \\
\hline Laos & 6.124129 & 34 & 5.510112 & 8 & 3.406930 & 36 \\
\hline Lebanon & 5.583838 & & 3.898901 & 25 & 2.473599 & \\
\hline Malaysia & 6.583375 & 22 & 3.468515 & 28 & 5.086940 & 16 \\
\hline Mongolia & 6.449908 & 26 & 2.938567 & 33 & 4.345383 & 23 \\
\hline Myanmar & 5.360117 & & 4.846579 & 16 & 4.658410 & 19 \\
\hline Nepal & 6.438746 & 27 & 7.282603 & 1 & 4.333382 & 24 \\
\hline Oman & 6.092499 & 36 & 2.037861 & & 3.317885 & \\
\hline Pakistan & 5.761872 & & 5.711356 & 6 & 3.673714 & 33 \\
\hline Philippines & 6.608736 & 21 & 6.261955 & 4 & 5.387364 & 13 \\
\hline Qatar & 5.002745 & & 1.521777 & & 5.840052 & 6 \\
\hline Russia & 6.885960 & 17 & 2.463854 & & 5.509223 & 11 \\
\hline Saudi Arabia & 6.978790 & 14 & 1.894613 & & 5.539684 & 9 \\
\hline Singapore & 7.398458 & 9 & 2.453777 & & 3.716562 & 31 \\
\hline Sri Lanka & 7.137873 & 12 & 6.398617 & 2 & 4.902276 & 18 \\
\hline Syria & 6.118476 & 35 & 4.342953 & 19 & 3.371204 & \\
\hline Taiwan & 8.240206 & 3 & 2.493648 & 36 & 6.463325 & 3 \\
\hline Tajikistan & 6.133682 & 33 & 5.314570 & 10 & 3.538427 & 34 \\
\hline Thailand & 7.342697 & 10 & 4.794439 & 17 & 5.675999 & 8 \\
\hline Turkey & 6.943129 & 16 & 3.920250 & 24 & 6.384393 & 4 \\
\hline Turkmenistan & 5.831608 & & 1.681455 & & 4.939937 & 17 \\
\hline UAE & 7.496620 & 8 & 1.872078 & & 6.843846 & 1 \\
\hline Uzbekistan & 6.563493 & 24 & 5.100018 & 13 & 3.976029 & 28 \\
\hline Vietnam & 6.706109 & 20 & 5.208638 & 11 & 4.542058 & 20 \\
\hline Yemen & 4.738153 & & 3.996337 & 22 & 1.791734 & \\
\hline
\end{tabular}


Although Kuwait is at the $5^{\text {th }}$ rank in economics well-being, when it comes to the environmental well-being it is at the bottom level. Oman experiences very lower ranks in every dimension. Sri Lanka is in a relatively higher position in all 3 dimensions. Turkmenistan and Qatar are in a very low rank in both human and environmental wellbeing although their economic well-being is within the first 20 ranks. The sustainable development in UAE is controversial since it is a country where the human and economic well-being is within first 10 ranks, nevertheless, environmental wellbeing takes the rank of 42 out of 44 countries. Yemen can be recognized as the country with lowest rank in both human and economic well-being.

The maps in Fig. 2,3 and 4illustrate visually the variabilityamong the 3 well-being types over the Asian countries in terms of relative ranking bydimension. The maps assess relative sustainability by metric in terms of rank among countries.

These color-coded maps for each individual metric are included to complement the tabular presentation of results. Presenting the metrics in map format offers a unique geographical visualization of the results. The maps provide a spatial presentation of what the world looks like in terms of relative sustainability according to the three dimensions.

The more consistent the results, the more similar the maps will appear. Conversely, the less consistent the results the less similar the maps will appear. Mapping results also provides a unique perspective of potential hotspot areas in terms of threatened sustainability. The other benefit of presenting the data in GIS format is that it is well suited for further decision-making analysis.

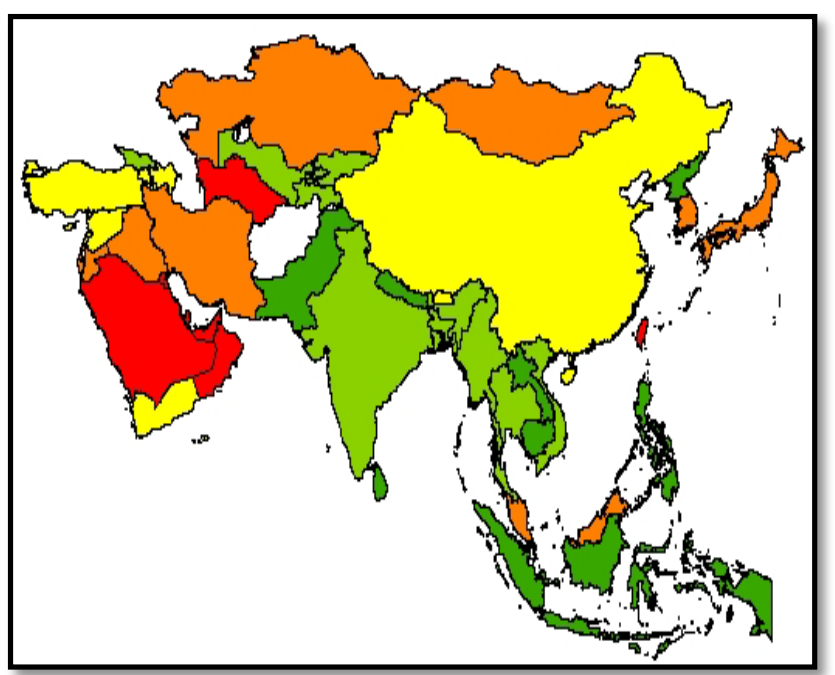

Dark green-top 20\% ranks, light green-next top 20\% ranks, yellow-middle $20 \%$ ranks, orange -lower $20 \%$ ranks, red- lowest $20 \%$ ranks

Fig. 2 Spatial Distribution of Environmental Well-being

Fig. 3 indicates the spatial distribution of environmental well-being over the Asian continent. It clearly depicts that South Asia, South-east Asian countries and half of Central
Asian countries dominate the top $40 \%$ ranks. China from East-Asia and some parts of Western Asia take middle 20\% ranks in environmental well-being whereas most of Middleeast countries, some parts of Central Asia and South Korea, Japan, Taiwan from East Asia make up the at the bottom $40 \%$ ranks.

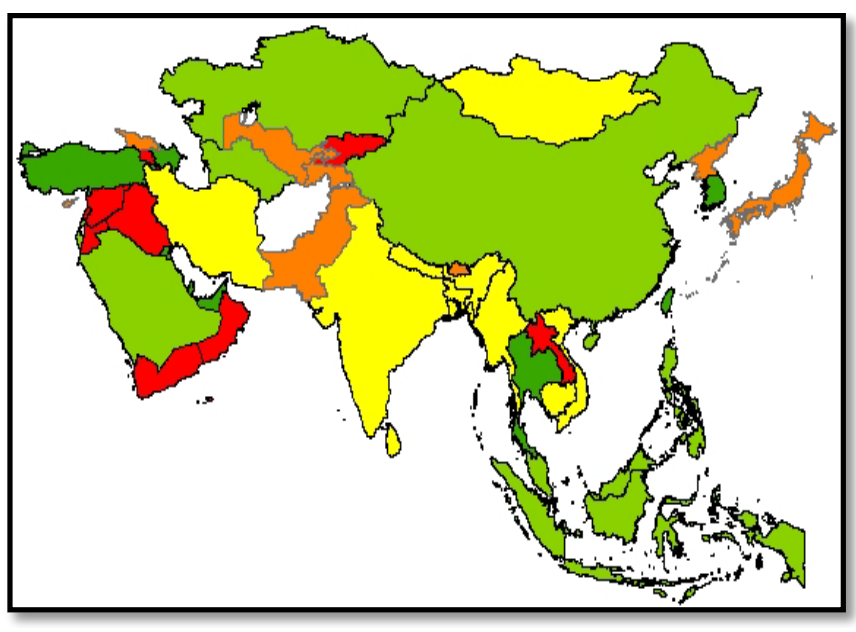

Dark green-top 20\% ranks, light green-next top 20\% ranks, yellow-middle $20 \%$ ranks, orange -lower $20 \%$ ranks, red- lowest $20 \%$ ranks

Fig. 3 Spatial Distribution of Economic Well-being

Fig. 4 indicates the spatial distribution of economic wellbeing over the Asian continent. The top $40 \%$ ranks are claimed by South-East Asia (except for Cambodia, Vietnam, Myanmar and Laos), China and 1/3 of the Middleeast countries. Most of the South-Asian countries, Cambodia, Vietnam, Myanmar from South-east Asia,Mongolia from East Asia and 1/3 of the Middle-east countries comprise the middle $20 \%$ ranks. The bottom $40 \%$ ranks of the economic well-being are covered by Laos, some parts of South-Asia, North Korea, Japan from East Asia, 1/3 of the Middle-east countries and 1/2 of the Central Asian countries.

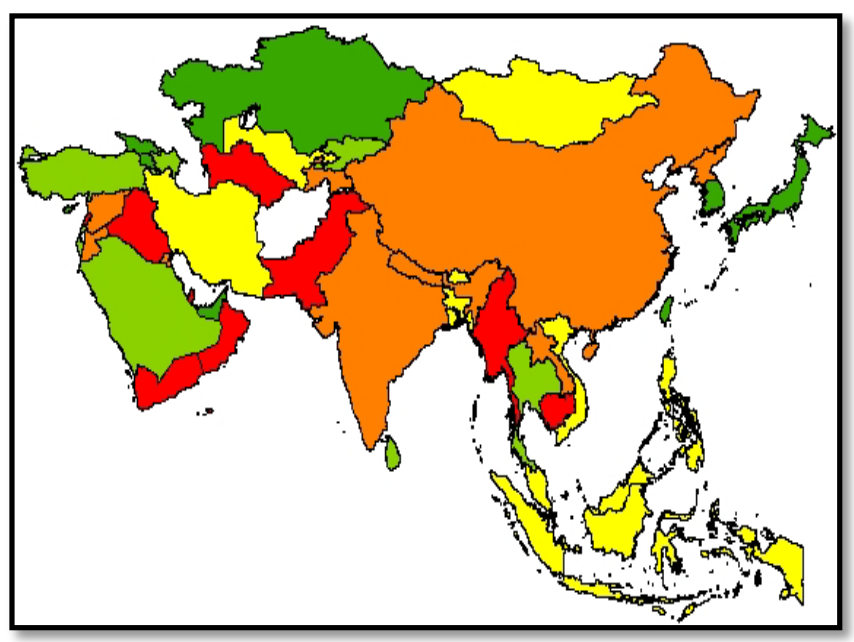

Dark green-top 20\% ranks, light green-next top 20\% ranks, yellow-middle $20 \%$ ranks, orange -lower $20 \%$ ranks, red- lowest $20 \%$ ranks

Fig. 4 Spatial Distribution of Human Well-being 
Fig. 5 portraits the distribution of human well-being over the Asian countries. Upper $40 \%$ ranks of this dimension are claimed by some parts of Middle-east, Kazakhstan, Kyrgyzstan of Central Asia, Sri Lanka, Thailand from South-East Asia and some part of East-Asia (Taiwan, South Korea and Japan).

The whole South-East Asian region (except for Thailand and Cambodia), Mongolia, some countries from Central Asia and Middle-east Asian region make up the middle $20 \%$ of the ranks. Almost all the South Asian countries, China, most of the Middle-east countries and Tajikistan and Turkmenistan from Central Asia are the countries which have the lowest ranks in the dimension of human wellbeing.

\section{B. Statistical Analysis}

Person correlation analysis was conducted among the three components of sustainable development in order to find out the presence of an association between each component.

Correlation: Human Wellbeing, Environmental Wellbeing, Economic Wellbeing

Human Wellbeing Environmental Wellbeing

Environmental Wellbeing $\quad-0.112$

0.468

Economic Wellbeing $0.400 \quad-0.294$

$0.007 \quad 0.048$

From the analysis we could find that there is no association between environmental well-being and human well-being (since $0.468>0.05$ ).

Nevertheless, according to the results it could be interpreted that there is an association between the economic wellbeing and the human well-being $(0.007<0.05)$ and the same was resulted for the economic and environmental well-being $(0.048>0.05)$. Both economic and human well-being have a positively strong association with each other while environment and economic wellbeing have a negative relationship.

It means that when the economic conditions of these Asian countries improve, the well-being of the people living in these countries also increases accordingly and when economy of the Asian countries improve the wellbeing of environment has decreased.

Study done by Asian Development Bank Institute also concluded that economic expansion and rising standard of living are being increasingly exposed to declining environmental conditions in Asia and remedial actions needed to be taken to protect the environment.

However, the solutions for the environmental degradation will be complex and time consuming (Howes \& Wyrwoll,
2012). A study done to find the relationship between environmental sustainability and economic growth in developing countries also proved that economic growth in high level will degrade environmental sustainability in developing countries (Samimi, et al., 2011). As most of the Asian countries come under the category of 'developing', these Asian countries have failed to maintain sustainable development as environmental degradation increasing significantly.

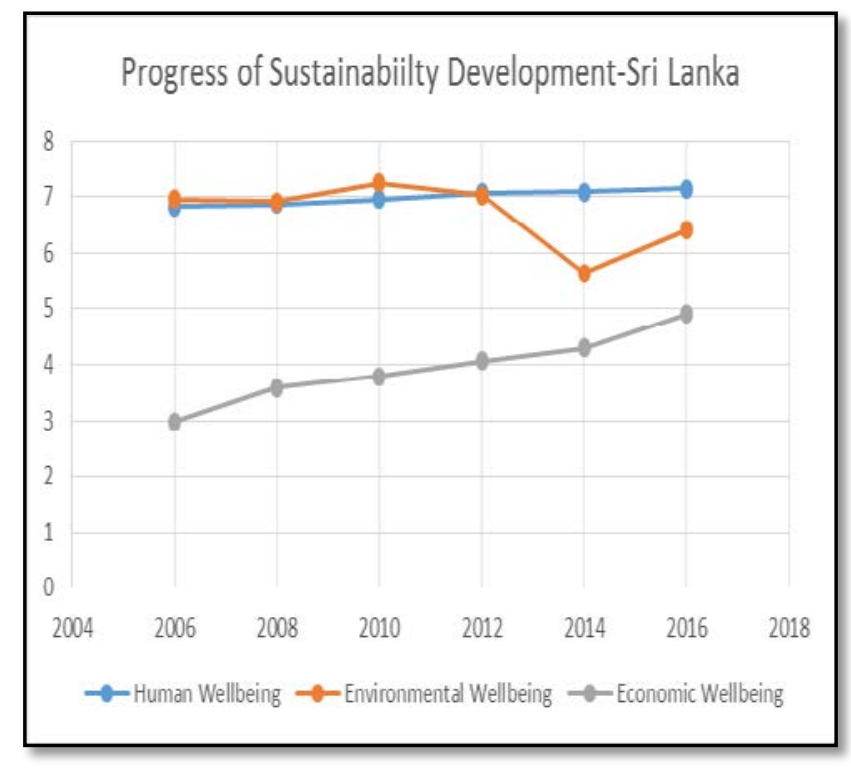

Fig. 5 Progress of Sustainability Development-Sri Lanka

The graph illustrates the changes taken place in the human, environment and economic well-being of Sri Lanka. Economic wellbeing has progressed steadily while human wellbeing also follows the same trend. However, Environmental wellbeing has taken a downfall until the year 2014 but, has recovered to a certain extent after the year 2014.

These results are in par with the review done by United Nations, 2018. As United Nations states the economy of Sri Lanka has had a noticible development. Poverty rate has dropped to $4.1 \%$ and the unemployment rate has stood below five percent. The human wellbeing has also improved and as a result, life expentancy has increased to 75 years and youth literacy rate increased to $98.7 \%$. However, this has come at a cost; Environmental degradation. Deforestation has increased as the result of high demand for land. As one of world's 35 biodiversity hotspots, Sri Lanka has greater challenge to ensure the environmental wellbeing through sutainable development.

Thus, Sri Lanka has enacted the sustainble development act in 2017 to formulate sutainable development policy and strategy. The prevailing government has adopted mainstreaming SDGs into institutional plans as its main strategy to achieve SDGs (United Nations, 2018). Remedy for environmental wellbeing has identifiied through National Biodiversity Strategic Action Plan. 


\section{CONCLUSION AND RECOMMENDATIONS}

The overall sustainable development of Asia currently lies in an unsatisfactory position. The current direction of environmental degradation in Asia is unsustainable. With the increase in economic well-being the human well-being has also increased but the environmental well-being has reduced with the increase of economic well-being. This indicates that countries of Asia lack sustainable development as a whole.

The development of countries in Asia, rapid industrialization and high rates of economic growth have been accompanied by environmental degradation. New policies need to be implemented and current Sustainable Development Goals suggested by United Nations should be incorporated into countries' sustainable development plans to ensure sustainable development of each and every country of the Asian continent.

It is argued that there should be a regional dimension in the environmental policies adopted in the Asian countries, as there are regional theories of economic growth. It also argues that the Asian countries may experience what may be termed 'impoverishing unsustainable growth' (Islam and Gigas, 1995) unless a set of appropriate policies are implemented immediately. Furthermore, focus should be given to ensure the wellbeing of environment as economic growth has badly impacted on environment of the countries of Asian Continent.

\section{REFERENCES}

[1] Asian Development Bank (ADB), (2019). ADB and the Sustainable Development Goals. Retrieved from https://www.adb.org/site/sdg/main [Accessed 0601 2019].

[2] Black, A., (2004). The quest for sustainable, healthy communities, presented to Effective Sustainability Education Conference, NSW Council on Environmental Education, UNSW, Sydney, 18-20 February.

[3] Brandon, C. \& Ramankutty, R., (1994). Toward an Environmental Strategy for Asia, World Bank - Discussion Papers 224, World Bank.

[4] Colantonio, A., (2007). Social Sustainability: An Exploratory Analysis of its Definition, Assessment Methods, Metrics and Tools. Measuring Social Sustainability: Best Practice from Urban Renewal in the EU, 2007/01: EIBURS Working Paper Series. Oxford Brookers University, Oxford.

[5] Daniel, R.,( 2018). The SDGs report card for Asia-Pacific is out, and the region is failing. Retrieved from https://www.sei.org/ featured/sdgs-report-card-asia-pacific-region-failing/ [Accessed 0601 2019].

[6] Diamond, J., (2005). Collapse: How Societies Choose to Fail or Survive. Viking Penguin/Allen Lane, New York and London.

[7] Dutton, J. A., (2017). The 3Ps and Triple Bottom Line. Retrieved from https://www.e-education.psu.edu/ba850/node/643 [Accessed 2411 2018].
[8] Empacher, C., Gotz, K. \& Schultz, I., (2002). Target group analysis of the Institute for Social-Ecological Research. Models of Sustainable Consumption: A New Ecopolitical Sphere of Action as a Challenge to Environmental Communication. Federal Environmental Agency, Forschung, Berlin, 87-181.

[9] Giddings, B., Hopwood, B. \& O'brien, G., (2002). Environment, economy and society: fitting them together into sustainable development. Sustainable development, 10(4), 187-196.

[10] Gilbert, R., (1996). Making cities work. In: The Role of Local Authorities in the Urban Environment. Earthscan, London.

[11] Goodland, R., (1995). The concept of environmental sustainability. Annual Review of Ecology and Systematics 26, 1-24.

[12] Hamrin R.D., (1983). A Renewable Resource Economy, Praeger, New York.

[13] Hansmann, R., Mieg, H.A. \& Frischknecht, P., (2012). Principal sustainability components: empirical analysis of synergies between the three pillars of sustainability. International Journal of Sustainable Development \& World Ecology, 19(5), 451-459.

[14] Islam, S. M. \& Jolley, A., (1996), November. Sustainable development in Asia: the current state and policy options. In Natural resources forum, 20(4), 263-279. Oxford, UK: Blackwell Publishing Ltd.

[15] Markandya, A., \& Pearce, D.W., (1988). Natural environments and the social rate of discount. Project Appraisal, 3(1), 2-12.

[16] Moldan, B., Janoušková, S. \& Hák, T., (2012). How to understand and measure environmental sustainability: Indicators and targets. Ecological Indicators, 17, 4-13.

[17] Saisana, M. \& Philippas, D., (2012). Sustainable Society Index (SSI):Taking societies' pulse along social, environmental and economic issues, Italy: European Union.

[18] Schoolman, E.D., Guest, J.S., Bush, K.F. \& Bell, A.R., (2012). How interdisciplinary is sustainability research? Analyzing the structure of an emerging scientific field. Sustainability Science, 7(1), 67-80.

[19] Serageldin, I., \& Streeter, A. (eds.), (1993). Valuing the environment: proceedings of theFirst Annual Conference on Environmentally Sustainable Development. Environmentally Sustainable Development Proceedings Series (2), The World Bank,Washington, D.C.

[20] Sustainable Society Foundation, (2017). Sustainable Society Index your compass to sustainability. Retrieved from http://www.ssfindex.com/contact-us/ [Accessed 2411 2018].

[21] UN, (2010). Sustainable Development. Retrieved from http://www.un.org/en/ga/president/65/issues/sustdev. shtml[Accessed 2411 2018].

[22] United Nations ESCAP, (2018). Sustainable Development. Retrieved from https://www.unescap.org/sustainable-development [Accessed 0601 2019].

[23] United Nations, (2013). World Economic and Social Survey (2013)Sustainable Development Challenges, New York: United Nations publication.

[24] Woolcock, M., (2001). The place of social capital in understanding social and economic outcomes. Canadian journal of policy research, 2(1), 11-17.

[25] World Bank, (2006). Where is the Wealth of Nations? Measuring Capital for the $21^{\text {st }}$ Century. WB, Washington, D.C.

[26] WDR, Development and the Environment, World Bank and Oxford University Press, (1992), ISBN: 978-0-19-520876-4

[27] Zahedi, K., (2018). Is Asia Pacific on track to meet the Sustainable Development Goals?. Retrieved from https://www.unescap.org/ blog/is-asia-pacific-on-track-to-meet-the-sustainable-developmentgoals[Accessed 0601 2019]. 